\title{
Comunicación corporativa de organizaciones que ofrecen recursos bibliotecarios en la Web
}

\author{
Por Ana Castillo-Díaz y Concepción-María Jiménez-Fernández
}

\begin{abstract}
Resumen: Se analiza la comunicación corporativa online de 17 instituciones del entorno de la biblioteconomía y la documentación, seleccionadas de entre las que figuran en el Anuario de Bibliotecas Españolas 2009 de la Fundación Alonso Quijano. Se analiza la eficacia de la gestión y la comunicación de las marcas presentes en sus portales, en base a un modelo diseñado al efecto. Las opciones comunicativas online afectan a la imagen y la reputación de las empresas y, por tanto, es fundamental cuidarlas.

Palabras clave: Recursos digitales, Descripción, Comunicación corporativa, Documentación, Marca.

Title: Corporate communication of organizations offering library resources on the Web

Abstract: We analyze the online corporate communications of 17 institutions of the library and information science area, selected from those contained in the Anuario de bibliotecas españolas 2009 (Spanish libraries yearbook) of the Fundación Alonso Quijano. We analyze the management and communication effectiveness of the brands present on their portals, based on a model designed for this purpose. Online communication options affect the image and reputation of companies and, therefore, it is essential to take care of them.
\end{abstract}

Key Words: Digital resources, Description, Corporate communication, Documentation, Branding.

Castillo-Díaz, Ana; Jiménez-Fernández, Concepción-María. "Comunicación corporativa de organizaciones que ofrecen recursos bibliotecarios en la Web". El profesional de la información, 2010, marzo-abril, v. 19, n. 2, pp. 184-188.

DOI: 10.3145/epi.2010.mar.09

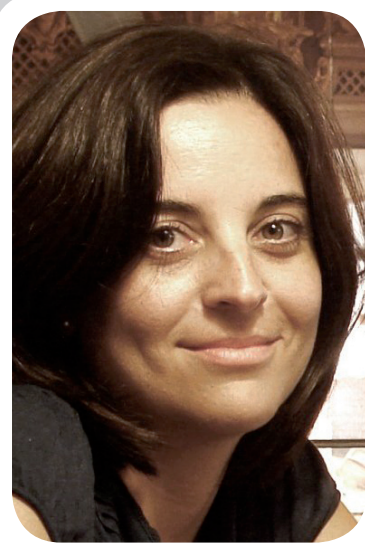

Ana Castillo-Díaz, doctora en comunicación por la Universidad de Extremadura (2007), licenciada en publicidad por la Universidad de Sevilla (1998), trabaja como profesora en titulación de Comunicación Audiovisual de la citada Universidad de Extremadura. Sus principales líneas de investigación son la comunicación corporativa online, la comunicación universitaria y la comunicación en pequeñas y medianas empresas (pymes). Es autora de los libros Imagen y comunicación en las pymes (Fragua, 2005) y Comunicación integral y responsabilidad social en las organizaciones (Pearson, 2009).

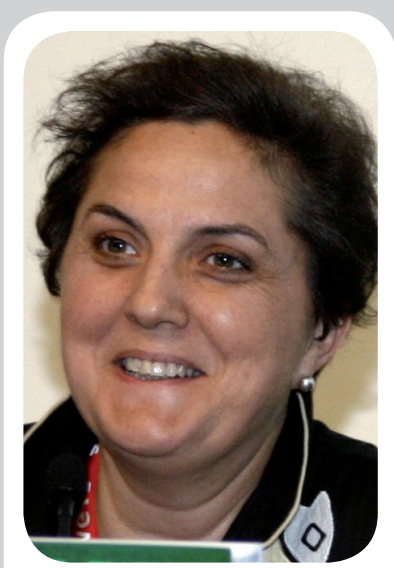

Concepción-María Jiménez-Fernández, diplomada en biblioteconomía y documentación por la Univ. de Granada, licenciada en documentación, y diplomada en estudios avanzados de comunicación y documentación por la Univ. de Extremadura, es doctorando en la Facultad de Traducción y Documentación de Salamanca. Subdirectora de la revista Mi Biblioteca, coordinadora del Anuario de Bibliotecas Españolas y responsable de la biblioteca pública municipal de Azuaga (Badajoz), ha publicado Animar a leer antes de leer y Abecedario de las bibliotecas municipales: una experiencia en la provincia de Badajoz.

\section{Concepto de marca y su manifestación en internet}

AUNQUE EL TÉRMINO MARCA continúa siendo uno de los más utilizados en el panorama del marketing actual, su origen se remonta a épocas muy tempranas en la historia de la humanidad.

Su nacimiento se puede situar ocho siglos antes de Cristo y su aplicación comenzó a extenderse para evitar los frecuentes robos en los almacenes de los alfareros. En la Edad Media la función de las marcas estaba controlada por las corporaciones y los gremios. Más adelante, en el industrialismo del siglo XVII, se impuso la libre competencia, la libertad de mercado y, así, se empezó a concebir la marca registrada como un activo de la empresa (Costa, 2001, p. 227).

Las ventajas que una buena imagen de marca puede reportar a una organización son numerosas. Según Ramos (2002, p. 46), disponer de una adecuada imagen de marca supone:

- Una condición de notoriedad y reconocimiento: el público sabe que existe.

- Diferenciación de la competencia.
- Ventajas a la hora de negociar las condiciones de distribución y la venta en la cadena comercial.

- Un factor de solvencia, como bien tangible, en las operaciones financieras de la empresa.

- Un valor de la organización de la que se pueden sentirse orgullosos sus miembros.

Ahondando en el concepto de marca, Alloza (2002, p. 223) describe la noción de marca experiencia: una denominación que se está empleando para designar la agrupación de todos los componentes de la marca de una organización. Se trata 
de un concepto integral y unificador que define a una corporación haciéndola única y se construye sobre la base de las experiencias que proporciona a sus diferentes públicos.

Es posible distinguir dos tipos de experiencia de marca (Villafañe, 2004, p. 46):

1) funcional, derivada de la satisfacción de una necesidad concreta, y

2) emocional, resultado del reconocimiento de unos valores sociales que el público ve en la marca, asociados a la ética y la responsabilidad social, y otros valores emocionales fruto de procesos de empatía o rechazo.

Cuando la experiencia vivida por los clientes es positiva, la marca se revaloriza.

En los contenidos de las marcas, por tanto, se aprecia una evolución desde los valores racionales hacia los emocionales y, finalmente, hacia la promesa de experiencia. Si se llevan a cabo planteamientos adecuados, a largo plazo es posible alcanzar una buena reputación de marca, que consiste en la identificación racional y emocional del público con una determinada marca, en la que reconoce una serie de atributos o valores que le proporcionan una experiencia positiva.

\section{"En los contenidos de las marcas se aprecia una evolución desde los valores racionales hacia los emocionales $y$, finalmente, hacia la promesa de experiencia"}

A pesar de la relativa juventud de internet, es posible ya describir una trayectoria de las marcas en ella. Según la evolución que refie- re De Chernatony (2003), en un primer momento muchos estrategas vieron el branding como la provisión de copiosos detalles de marca, entendiendo la marca en la Red como un centro de datos. Pronto se dieron cuenta de que si las marcas iban a prosperar en este entorno era preciso un mayor acercamiento al "cliente como centro", a quien se comenzó a brindar información a medida. Por tanto, durante un tiempo el foco continuó siendo principalmente la información, aunque ya se trataba de una información elaborada a medida.

Dando un paso más, muchas organizaciones no se limitan a considerar la Web como un medio pasivo, que simplemente actúa como un conducto de información, sino que tratan de suministrar a través de ella una experiencia envolvente a sus públicos como socios de confianza (no ya sólo como clientes). En este dinámico territorio la interacción de los distintos públicos aumenta el valor y la confianza en la marca.

Teniendo en cuenta lo expuesto es fundamental que en las sedes web corporativas, además del contenido que las marcas aportan como servicio, se incluya información de carácter corporativo que presente a la organización y la muestre como una institución fiable y confiable ante sus públicos.

\section{Selección de la muestra y metodología}

Con el propósito de poner orden y actuar como guía facilitando una información precisa que indique la localización de los recursos de interés para bibliotecarios, así como una pequeña descripción de los mismos, desde 2008 la Fundación Alonso Quijano viene editando el Anuario de Bibliotecas Españolas. Consta de dos partes: la primera referida a las bibliotecas españolas y la segunda consistente en un directorio de fuentes útiles para profesionales, bibliotecas y usuarios.
Para delimitar la muestra de este trabajo se ha considerado una de las secciones del Anuario, en concreto la que trata los portales de recursos bibliotecarios, donde se recogen enlaces y servicios de interés profesional. Dentro de éstos se han seleccionado 17 que aportan información sobre fuentes generales y de investigación (tabla 1).

En el Anuario se listan algunas webs personales, cuyo objetivo escapa al interés de marca, y que por tanto han sido excluidas del análisis, centrándose éste en la revisión de los portales profesionales puestos en marcha por empresas e instituciones. Este criterio de selección posibilita posteriormente establecer comparaciones entre factores de similar naturaleza.

Se efectuó un análisis de los mensajes relacionados con la marca que sustenta dichos portales.

Para evaluar las marcas contenidas en las webs se ha atendido a los siguientes indicadores:

- Existencia de mensajes. En ocasiones el mensaje puede aparecer de manera implícita, sin ser expresado nítidamente. Ese es el punto de partida de la puntuación positiva (1). Cuanta mayor claridad y contundencia manifiesta el mensaje, mayor fue la puntuación otorgada (2 ó 3). Obviamente, si no existen mensajes, el resto de variables no se valoran.

- Ubicación de los mensajes. La estructura jerárquica de la información determina la cantidad de pasos (clics) que se necesitan para acceder a un determinado contenido (Lynch; Horton, 2004). Atendiendo a los patrones identificados en la lectura de las webs (Nielsen, 2000) se estima que cuanto más profundo sea el nivel donde se encuentre la información, menor será la posibilidad de que el público acceda a ella, ya que se requiere mayor tiempo de permanencia y búsqueda. La puntuación que se ha otorgado a cada 


\begin{tabular}{|c|c|}
\hline Título & URL \\
\hline @bsysnet.com & http://www.absysnet.com \\
\hline Complured & http://alfama.sim.ucm.es/complured \\
\hline Documentarium & http://www.documentarium.info/home/index.php \\
\hline Docuweb & http://www.docuweb.es \\
\hline Enlaces de bibliotecas & http://www.terra.es/personal/bibliot1/\#enlaces \\
\hline Universidad de Salamanca, Bibliotecas & http://exlibris.usal.es/merlo/materias/biblio/enlaces.htm \\
\hline Fundación Ciencias de la Documentación & http://www.documentalistas.org \\
\hline MetaBase: Bibliografía en Red & http://www.metabase.net \\
\hline Ministerio de Cultura. Bibliotecas & http://www.mcu.es/bibliotecas/index.htm/ \\
\hline Universidad de La Rioja, Rebiun & http://aps. unirioja.es/biblio/recursos?sub=2 \\
\hline RecBib, Recursos bibliotecarios & http://www.recbib.es \\
\hline Diputación de Albacete, Bibliotecas & http://www.dipualba.es/bibliotecas/pozoca/recursosbibliotecarios. $h$ tm \\
\hline CSIC, Bibliotecas & http://bibliotecas.csic.es/recursos/recurbd.htm/ \\
\hline Universidad de León & http://www3.unileon.es/dp/abd/recursguias.htm \\
\hline Redib & http://www.felixherreradiez.com \\
\hline Travesía & http://travesia.mcu.es/portalnb/jspui/index.jsp \\
\hline Universia & http://biblio. universia.es/recursos/index.htm \\
\hline
\end{tabular}

Tabla 1. Portales bibliotecarios analizados

nivel se muestra en la siguiente tabla:

\begin{tabular}{|lc|}
\hline Acceso desde: & puntos \\
la página principal & 3 \\
un segundo nivel & 2 \\
un tercer nivel & 1 \\
niveles superiores al tercero & 0 \\
\hline
\end{tabular}

\section{"Cuanto más profundo sea el subdirectorio donde se encuentra la información, menor será la posibilidad de que se acceda a ella"}

-Adaptación de los mensajes a los distintos stakeholders ${ }^{1}$ o público objetivo.

Pollach (2005) se plantea la utilidad de las secciones "about us" para la autopresentación de las organizaciones cuando no están orientadas a ningún perfil de au- diencia en particular. Por su parte, Nielsen (2000, p. 15) apunta que uno de los errores más comunes en el diseño web es el de "estructurar el sitio para que refleje el organigrama de la empresa. En vez de ello, el sitio debe mostrar los temas de interés para los usuarios y dar cabida a sus puntos de vista en el espacio informativo". Se entiende que el valor del mensaje se acrecienta si se presenta de manera personalizada a cada grupo de público de interés para la institución, ya que esto conlleva una mayor adaptación a las características e intereses de cada uno.

\begin{tabular}{|ll|}
\hline \multicolumn{2}{|c|}{ - Adaptación del contenido } \\
a distintos públicos & 2 puntos \\
-Consideración de & \\
perfiles genéricos & 1 \\
-Sin adaptación & 0 \\
\hline
\end{tabular}

- Traducción de los mensajes.

La traducción de los mensajes a idiomas extranjeros se valora positivamente por lo que significa de proyección internacional de la institución. Es una estrategia para atraer a posibles stakeholders de otras nacionalidades, e incluso de la propia.

\begin{tabular}{|ll|}
\hline -Traducción a dos & \\
idiomas o más & 2 puntos \\
-Traducción a un idioma & \\
extranjero & 1 \\
-Sin traducción & 0 \\
\hline
\end{tabular}

\section{"La traducción del contenido a otros idiomas puede reportar la posible expansión internacional de la marca"}

- Refuerzo del contenido de los mensajes con contenidos visuales o audiovisuales.

Con este refuerzo los mensajes presentan una mayor potencia de recuerdo. La facultad de las impresiones para activar las emociones humanas ha sido observada desde épocas remotas (Gombrich, 1991). 
La posibilidad de hacer una lectura correcta de la imagen se rige por tres variables: el código, el texto y el contexto. La palabra y la imagen combinadas aumentan la probabilidad de hacer una (re)construcción correcta de los mensajes que se desea transmitir. El apoyo mutuo del lenguaje y la imagen, por tanto, facilita la memorización. La puntuación asignada a los refuerzos audiovisuales es mayor (2) que a los de imágenes fijas (1).

\section{Resultados}

Tras revisar los portales en función de la plantilla descrita observamos que sólo la mitad de estas instituciones facilitan mensajes explícitos sobre las características de su marca.

En general se aprecia que la ubicación de los contenidos relacionados con sus marcas es correcta, ya que el $78 \%$ de los portales analizados los sitúa en la primera o primeras páginas de navegación del usuario. Sólo un 11\% los sitúan en el tercer nivel de navegación o en zonas inferiores.

Las variables más deficientemente desarrolladas en la mayoría de los portales son la adaptación de la información corporativa a las características de su público objetivo, y la traducción del contenido a otros idiomas.

La mayor parte de las webs estudiadas tiene una estructuración de la información temática y no se presenta ningún tipo de adaptación de la información en función de las características y necesidades que pudieran tener los distintos perfiles de públicos. Sólo 2 tienen algún tipo de adaptación en este sentido.

Sólo una cuarta parte de las webs han traducido contenidos relacionados con sus marcas a otros idiomas. La traducción sería conveniente para que personas de otros países pudiesen tomar contacto con la marca, conocer sus servicios y posiblemente ser usuarios de la misma.

Tampoco abundan los refuerzos audiovisuales que pudieran complementar los mensajes textuales que describen las marcas que hay tras los portales revisados y, en caso de existir, suelen consistir en fotografías estáticas, en lugar de vídeos que pudieran aportar más credibilidad a la imagen de marca.

\section{Recomendaciones}

Atendiendo a los resultados se presenta una serie de recomendaciones que podrían resultar de interés a los autores de webs dirigidas a bibliotecarios-documentalistas:

- Presentar con mayor nitidez y contundencia los mensajes corporativos. No sólo se trata de proporcionar información de calidad, sino que en un entorno tan competitivo como es internet es preciso que la marca hable sobre sí misma, que informe sobre sus ventajas diferenciales sobre la competencia y que contribuya a su correcto posicionamiento en la mente del receptor. Si se emplea tiempo en seleccionar, organizar y presentar la información para los usuarios, ¿por qué no hacer esto extensible a los mensajes corporativos?

- En los portales cuyo servicio se orienta a distintos tipos de públicos es conveniente la consideración de perfiles, más allá de la agrupación temática de contenidos. Se ha observado que en la mayoría de portales los contenidos de organizan en función de temas. No obstante, habría que tener en cuenta que no todos los interesados presentan las mismas características ni se acercan a los portales con las mismas necesidades. Además, dado el escaso tiempo de permanencia de los internautas frente a las páginas web resulta fundamental que se le facilite información de valor, debidamente estructurada y adaptada a sus intereses particulares.
- Un aspecto que mejoraría las webs es su traducción a idiomas extranjeros. Los mensajes corporativos no suelen variar con frecuencia, como les sucede a las páginas de noticias, por ejemplo. Así, colocar una traducción de estos contenidos a otros idiomas en los primeros niveles de navegación de la web no supondría un gran esfuerzo. Esta traducción le reportaría el beneficio de la posible expansión internacional de sus mensajes de marca.

- Ya se ha comentado la utilidad de la incorporación de imágenes y vídeos corporativos a este tipo de portales. Con las posibilidades actuales de los equipos y las conexiones, incluir algún refuerzo de carácter audiovisual no ocasiona ningún inconveniente para la correcta carga de las páginas web y aporta mucho valor al mensaje que se pretende trasladar a los receptores.

\section{Nota}

1. Grunig y Repper (1992, pp. 124-127) y Dowling (1994, pp. 22-24) introdujeron este concepto. Los stakeholders son definidos como públicos de interés para una organización; personas vinculadas a una organización porque ambos se influyen mutuamente ("people who are linked to an organization because they and the organization have consequences on each other" (Grunig y Repper, 1992, p. 125). En muchas empresas aún hoy persiste la creencia de que sus verdaderos públicos son los accionistas y socios (stockholders) sin prestar demasiada atención a la totalidad de públicos de la organización.

\section{Bibliografía}

Alloza, Ángel. "La gestión estratégica de la marca". En: Villafañe, J. (dir.): El estado de la publicidad y el corporate en España y Latinoamérica. Madrid: Pirámide, 2002, p. 223.

Benavides, Juan. "Nuevas reflexiones sobre internet”. En: Benavides, J.; Alameda, D.; Villagrá, N. (eds.): Los espacios para la comunicación en el año 2000. Madrid: FGUCM, 2001, p. 162.

De Chernatony, Leslie. Brand building on the internet.

http://www.business.bham.ac.uk/research/marketing/crbm/papers.shtml

Costa, Joan. Imagen corporativa en el siglo XXI. Buenos Aires: La Crujía, 2001, ISBN 987-100437-0.

Dowling, Grahame R. Corporate reputations: strategies for developing the corporate brand. London: Kogan Page, 1994. ISBN 0-582-915597. 
Gombrich, Ernst H. "La imagen y el ojo". En La imagen visual: su lugar en la comunicación. Madrid: Alianza Editorial, 1991.

Grunig, James E.; Repper, Fred C. "Strategic management, publics, and issues". In: Grunig, J E. (ed.): Excellence in public relations and communication management. Hillsdale: Lawrence Erlbaum, 1992, pp. 117-157

Jiménez-Fernández, Concepción-María (coord.). Anuario de bibliotecas españolas 2009. Málaga: Fundación Alonso Quijano, 2009.

Lynch, Patrick; Horton, Sarah. Manual de estilo web. Barcelona: Gustavo Gili, 2004. ISBN 84-252-1942-6

Maldonado-Martínez, Ángeles; Rodríguez-
Yunta, Luis (coords.). La información especializada en Internet: directorio de recursos de interés académico y profesional. Madrid: CSIC, 2006. ISBN 84-00-08436-5.

Nielsen, Jakob. Usabilidad. Diseño de sitios web. Madrid, Prentice Hall, 2000. ISBN 84-2053008-5.

Pollach, Irene. "Corporate self-presentation on the WWW. Strategies for enhancing usability, credibility and utility". Corporate communications: an international review, v. 10, n. 4, 2005 , pp. 285-301

Ramos, Fernando. La comunicación corporativa e institucional. De la imagen al protocolo. Madrid: Universitas, 2002. ISBN 84-7991-139-5.
Villafañe, Justo. La buena reputación. Claves del valor intangible de las empresas. Madrid: Pirámide, 2004. ISBN 84-368-1839-3

Ana Castillo-Díaz, Universidad de Extremadura

acasdia@alcazaba.unex.es

Concepción-María Jiménez-Fernández, Fundación Alonso Quijano

redaccion@mibiblioteca.org

\section{Indización de fotos y emotividad de un banco}

$H S B C$ se ha hecho famoso por sus campañas de "un banco mundial que entiende los valores locales". Presenta unas mismas fotos rotuladas con una sola palabra que interpreta diferentes significados. He aquí un par de ejemplos de anuncios recientes:

\section{Responsabilidad}

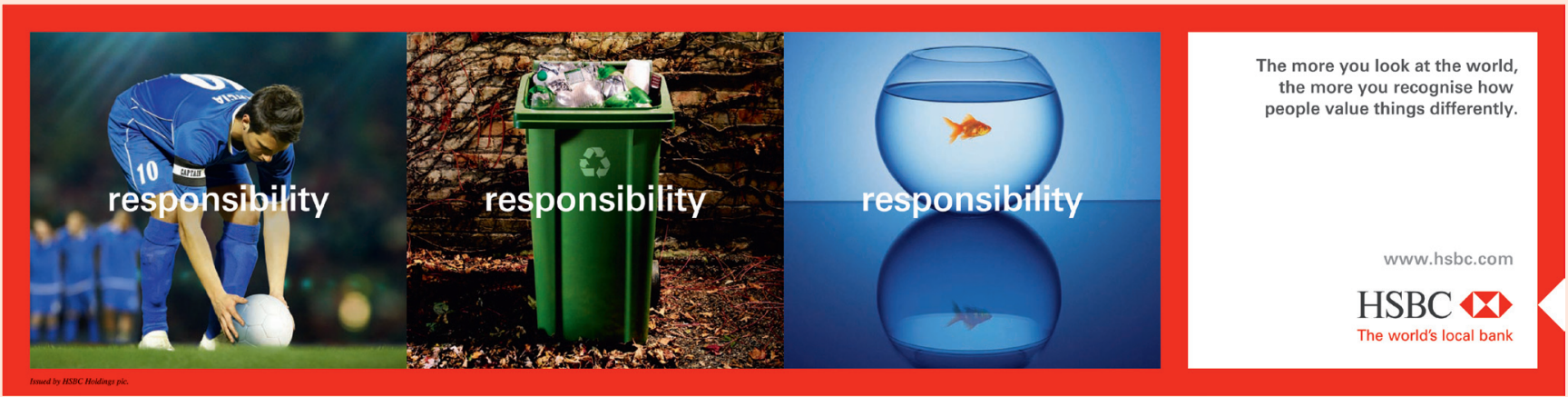

\section{Confianza}

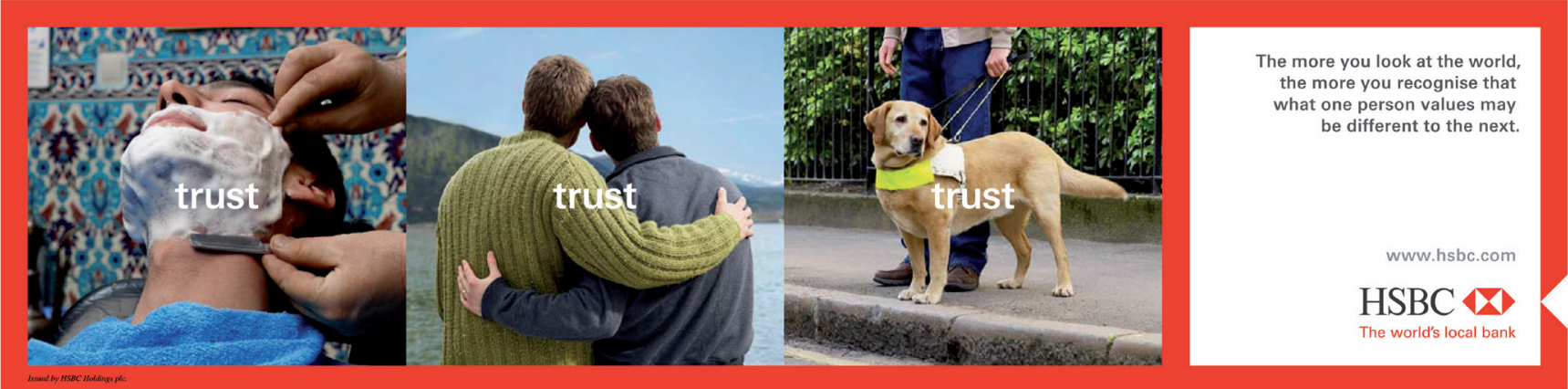

En sus impecables spots para la tele, $H S B C$ lanza mensajes sobre la diversidad y los valores humanos, con contenidos altamente emotivos. Los dos más recientes (aún visibles en su web) muestran personas que
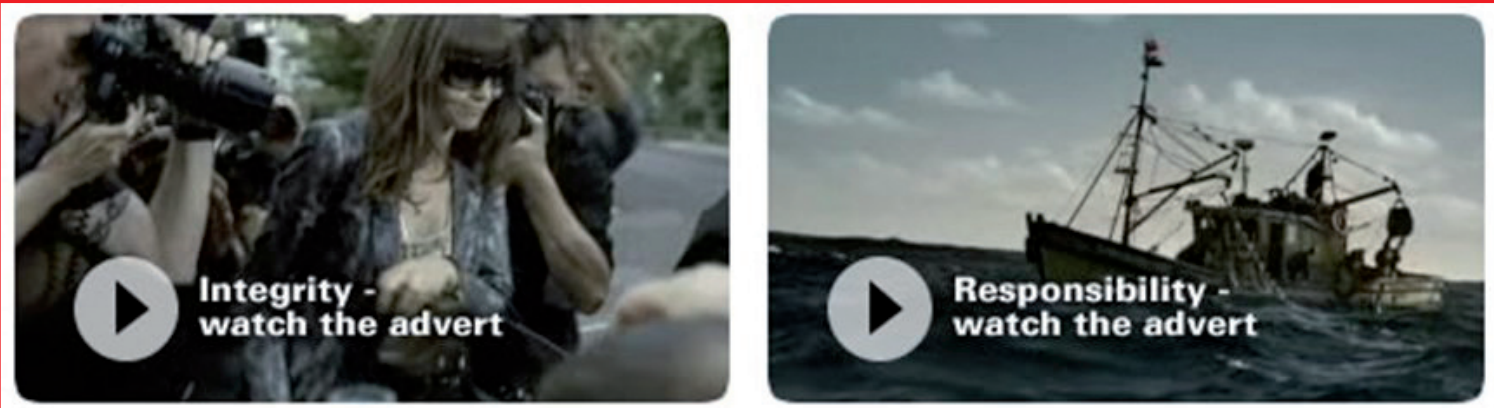

reaccionan honestamente a pesar de perder dinero con la decisión que toman. 